\title{
Gamma-Glutamylcysteine Synthetase
}

National Cancer Institute

\section{Source}

National Cancer Institute. Gamma-Glutamylcysteine Synthetase. NCI Thesaurus. Code C16602.

Glutamate-cysteine ligase, also known as gamma-glutamylcysteine synthetase is the first rate limiting enzyme of glutathione synthesis. The enzyme consists of two subunits, a heavy catalytic subunit and a light regulatory subunit. The gene encoding the catalytic subunit encodes a protein of 367 amino acids with a calculated molecular weight of $72.773 \mathrm{kDa}$ and maps to chromosome 6. The regulatory subunit is derived from a different gene located on chromosome 1p22-p21. Deficiency of gammaglutamylcysteine synthetase in human is associated with enzymopathic hemolytic anemia. (LocusLink) 